\title{
EDUCATING NURSES TO PROVIDE BETTER CARE FOR THE MILITARY VETERAN AND THEIR FAMILIES
}

EDITORIAL by Alan Finnegan, Stephen McGhee and Jonathan Leach.

\section{INTRODUCTION}

Military Veterans and their families are a diverse heterogeneous group that differ by factors such as age, gender, and length of service. In many countries, they are embedded in the fabric of nearly every layer of society. On completion of a military career, many veterans transition to a civilian community in which they thrive. The majority use the personnel growth associated with military service to forge successful careers and use their experience for the benefit of humanity. However, others may experience difficulty reintegrating into civilian life, facing housing, education, training and employment challenges with higher unemployment rates for both men and women then the general population. ${ }^{1}$ In addition, many of these public servants witness horrendous events, including death to friends, colleagues and civilians of all ages including children. This may result in an operationally attributable Mental Health (MH) disorder including Post Traumatic Stress Disorder (PTSD). Therefore, assisting veterans to deal with $\mathrm{MH}$ challenges resulting from service to their respective country has gathered pace in recent years. This being a result of the extensive demands placed on military personnel and their families during the recent campaigns in Iraq (2003-2011) and Afghanistan (2001-1014). However, many Veterans are unwilling to disclose problems associated with their former military life, often believing that civilians including healthcare professionals do not understand military culture and therefore cannot appreciate their individuality.

These reports that veterans do not disclose detail of their military experiences because clinicians "do not understand" has been accepted for too long. Military Veterans and their families need nurses and fellow health and social care professionals that are knowledgeable of the specific demands associated with a military career, and who are empowered to address these issues in a language and approach that veterans and their families understand. Nurses, health care providers, educators and social services are ideally positioned to make a significant difference in the care of veterans and their families. To achieve this, there needs to be a formal recognition of the requirements and a structured and consistent educational syllabus to meet their needs. Core curriculum detail needs to stem from an empirical basis to support colleagues in promoting and providing a comprehensive, systematic and structured educational portfolio to best meet the needs of the armed forces community.

The USA through its Veterans Health Administration have an established healthcare system for supporting veterans. However, producing a nursing and clinical workforce that specifically have skills sets and competencies to care for this veteran population has only recently gained momentum. In 2011, First Lady Michelle Obama and Dr. Jill Biden's launched a JOINING FORCES initiative which led to 500 USA nursing educational institutions committing resources and effort to improving the healthcare of the armed forces community supported by philanthropists' such as the Jonas Foundation. The primary focus being nurses as they form the largest single professional group, and subsequently, multiple

\footnotetext{
${ }^{1}$ United States Department of Labor. (2014, March 14, 2014). Bureau of Labor Statistics, 2014, from http://www.bls.gov/news.release/vet.toc.htm
} 
USA initiatives have been introduced and evaluated. This includes a broad range of undergraduate and postgraduate educational programme including a variety of teaching methodologies. The result has been the stimulation of a multi-faceted academic model that comprehensively addresses education, research, and employment initiatives for improving health and wellbeing for the armed forces community. Nurse Education Today showed many of these initiatives within a Military Veterans Special Issue (December 2016).

There is scope for other countries and other disciplines to employ similar initiatives. In the UK, The Royal College of General Practitioners has embedded veterans' health as a mandated core curriculum in GP training. This is being extended (in collaboration with the National Health Service) with nursing support to produce a standardized and manualized Primary Healthcare training programme that can be delivered in local health care practices. Despite this, there remains is no universal, structured and systematic approach to educating health or social care personnel to deliver this care.

To address this, another UK educational initiative is targeting student nurses currently undertaking an under-graduate programme. These students will progress to join the 680,000 nursing workforce, forming the critical mass of healthcare professionals. UK nursing academics with the support of the President of the Royal College of Nursing (RCN) and the Winston Churchill Memorial Fund are tackling this issue from another angle, with an intent to translate the US initiatives into a UK academic model to ensure that all under-graduate students gain experience of veteran health and social care. This stepped approach will result in a one session delivered in each of the students 3 year training course, and is being developed at the University of Chester and piloted with 2 other Universities in the North West of England. The intent is to embrace advancing technologies and online courses in order to reach out to the clinical workforce, with the initial primary beneficiaries being the UK armed forces community.

The aim is to develop a culture that permeates a military focus throughout UK universities to create future nursing and medical leaders with a better insight into this large, diverse Armed Forces population. Thereby increasing support through partnerships, funding, access to resources, college promotion, and community good will. Importantly, the UK model is being fully evaluated with measurable outcomes. If statutory professional bodies such as the UK Nursing Midwifery Council are to be consulted regarding the introduction of veterans care into core curriculum, then suitable empirical evidence is required. The initial findings from the UK evaluation will be presented at an International Veterans Conference at the University of Chester, England on 5 Oct 2017. Dissemination of the findings will be optimized through engagement with the professional bodies such as the American Academy of Nursing and the RCN, Service Charities and National Armed Forces including the Australian, British, and the USA. A well-educated and knowledgeable clinical workforce can provide the optimum care that this population deserve. 